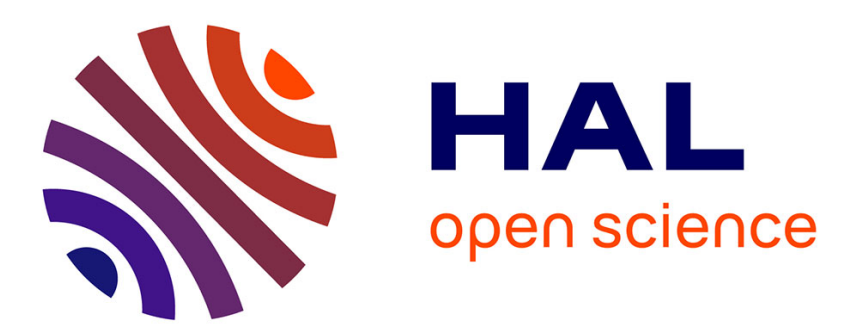

\title{
Biodegradation by bioaugmentation of dairy wastewater by fungal consortium on a bioreactor lab-scale and on a pilot-scale
}

\author{
Hayet Djelal, Abdeltif Amrane
}

\section{> To cite this version:}

Hayet Djelal, Abdeltif Amrane. Biodegradation by bioaugmentation of dairy wastewater by fungal consortium on a bioreactor lab-scale and on a pilot-scale. Journal of Environmental Sciences, 2013, 25 (9), pp.1906-1912. 10.1016/S1001-0742(12)60239-3 . hal-00871961

\section{HAL Id: hal-00871961 https://hal.science/hal-00871961}

Submitted on 11 Oct 2013

HAL is a multi-disciplinary open access archive for the deposit and dissemination of scientific research documents, whether they are published or not. The documents may come from teaching and research institutions in France or abroad, or from public or private research centers.
L'archive ouverte pluridisciplinaire HAL, est destinée au dépôt et à la diffusion de documents scientifiques de niveau recherche, publiés ou non, émanant des établissements d'enseignement et de recherche français ou étrangers, des laboratoires publics ou privés. 


\title{
Biodegradation by bioaugmentation of dairy wastewater by fungal consortium on a bioreactor lab-scale and on a pilot-scale
}

\author{
Hayet Djelal ${ }^{1,3, *}$, Abdeltif Amrane ${ }^{2,3}$ \\ 1. Trades School of the Environment, Campus de Ker Lann, 35170 Bruz, France \\ 2. University of Rennes 1, ENSCR, CNRS, UMR 6226, Avenue du General Leclerc, CS 50837, 35708 \\ Rennes Cedex 7, France
}

3. European University of Brittany, 5 Laennec Boulevard, Rennes, France

\begin{abstract}
A fungal consortium including Aspergillus niger, Mucor hiemalis and Galactomyces geotrichum was tested for the treatment of dairy wastewater. The bio-augmentation method was tested at lab-scale $(4 \mathrm{~L})$, at pilot scale $(110 \mathrm{~L})$ and at an industrial scale in Wastewater Treatment Plants (WWTP). The positive impact of fungal addition was confirmed when fungi was beforehand accelerated by pre-culture on whey ( $5 \mathrm{~g} / \mathrm{L}$ lactose) or on the dairy effluent. Indeed, Chemical oxygen demand (COD) removal yields increased from 55\% to $75 \%$ for model medium, diluted milk. While after inoculation of an industrial biological tank from a dairy factory with the fungal consortium accelerated by pre-cultivation in a $1000 \mathrm{~L}$ pilot plant, the outlet COD values decreased from values above the standard one $(100 \mathrm{mg} / \mathrm{L})$ to values in the range 50-70 $\mathrm{mg} / \mathrm{L}$. In addition, there was a clear impact of fungal addition on the 'hard' or non-biodegradable COD owing to the significant reduction of the increase of the COD on $\mathrm{BOD}_{5}$ ratio between the inlet and the outlet of the biological tank of WWTP. It was in the range $451 \%-1111 \%$ before fungal add, and in the range 257 and $153 \%$ after bio-augmentation with fungi. An inoculated bioreactor with fungal consortium was developed at lab-scale and demonstrated successfully at pilot scale in WWTP.
\end{abstract}

Key words: dairy wastewater; biodegradation; bioaugmentation; fungi; wastewater treatment DOI:

*Corresponding author. E-mail: hayetdjelal@ecole-eme.com

\section{Introduction}

The management of wastewater coming from manufacturing processes is a central point for the dairy industries. The effluents of these industries are especially composed from rinsing waters (50 at $90 \%$ of the total volume) of the trucks and tank, and the detergents used 
to clean those. There is also a small quantity of dairy products (1 to $3 \%$ of the transformed milk) due to losses along the process (Kushwaha et al., 2010, Muangrat et al., 2011). The effluents, rejected by the company before treatment, have a high $\mathrm{pH}$ as well as a high biochemical oxygen demand (BOD), because of the detergents and milk (Moir et al., 2005, Alvareza et al., 2007, Morin et al., 2007). Some physico-chemical processes have been implemented for the treatment of dairy effluent such as Osmosis Membranes (Del Re et al., 1998, Balannec et al.; 2005, Sarkar et al., 2006), ultrafiltration (Luo et al., 2012) or electrochemical treatment (Kushwaha et al., 2010). Nevertheless, these processes had an inherent drawback due to high operating costs from either the use of external acid sources or flocculating agents (Seesuriyachan et al., 2009).

Biological treatments have been already demonstrated that they are among the most advantageous methods for maximising recycle and recovering their components (Demirel et al., 2005, Forster-Carneiro and Romero, 2008, Wu et al., 2011). But high level of organic matter (OM) may pose a serious problem to the conventional wastewater treatment plant (activated sludge) in decreasing chemical oxygen demand (COD) owing to the presence of refractory organic matter (Seesuriyachan et al., 2009).

There is an increasing cost of excess sludge treatment and disposal owing to the strictly enforced environmental and legislative requirements on the discharge of excess sludge (Low and Chase, 1999; Wei et al., 2003a, 2003b). Therefore, the use of a specific microbial biomass comes to be the most economic and efficient solution to reduce excess sludge (Huang et al., 2007). A viable alternative is bio-augmentation strategies, such as the addition of external microorganisms with high capacity for the specific degradation of a target substrate (Loprena et al., 2006, Loprena et al., 2007, Chen at al., 2012). The use of a specific fungal biomass for the elimination of organic pollutants has been the subject of a lot of studies which permitted to confirm this choice (Giraud et al., 2001; Beary et al., 2002; Bhalerao and Puranik, 2006). Different techniques and bacterial and/or fungal consortium were produced and are now available on the industrial wastewater treatment market. These products consist of non-pathogenic naturally occurring microorganisms that have compatible, complementary and synergic capacities for degrading a given substrate (Loprena et al., 2006). Studies have shown that mixed cultures of fungi enable a greater production of enzymes responsible for the degradation of organic matter (Deepack, 1994).

Applications in industrial wastewater treatment showed efficacy on the biodegradation of refractory organic matter by biological conventional treatment and by reducing the sludge volume. The industrial sites studied were dairy, paper and sugar industries (Djelal et al., 2007; 
Lapadatescu et al., 2010). The development of the MycET® process was carried out by the Directorate of Development SAUR and was based on the use of fungi to reduce the volume of sludge. The various fungi (strains mycelium) which compose the cocktail were identified and isolated by the SAUR and associated with sludge for seeding the process. A sustainable development approach constitutes the interest of the MycET® process. (www.aquatech.limoges.free.fr, www.paysdeluxeuil.fr, www.novethic.fr).

The purpose of this study was to improve the treatment of dairy effluent without produce more sludge by bio-augmentation with fungal consortium. So a bioreactor was developed to amplify the fungal consortium before the inoculation in tank biological of dairy plant WWTP.

Indeed, the few available works remain at lab-scale or pilot scale, but not at an industrial scale as it is the case in this work. The first task was therefore to determine the optimal conditions of growth and COD removal with high outputs of COD in the dairy effluent, before proceeding on an industrial scale.

\section{Material and methods}

\subsection{Media}

Three culture media were tested: (1) A synthetic one containing whey as a byproduct of dairy farm activity: sweet whey powder was used, reconstituted to achieve the required lactose concentration. (2) A synthetic dairy wastewater solution of milk diluted in water: there is a variability of dairy wastewater depending on the considered industrial site and the manufactured products. However, and even if the effluent characteristics varied with time (flow rates, loads, $\mathrm{pH}$, fat....), the mean composition remains close to that of milk, taking into account the dilution factor. The model effluent used in this work was based on commercial milk sterilized by high temperature treatment (UHT), semi-skimmed milk diluted 40 times with tap water to achieve characteristics which are in the range of values measured on the usual dairy wastewaters, namely about $1.25 \mathrm{~g} / \mathrm{L}$ of total sugars. The used UHT half-skimmed milk had the following composition (for $100 \mathrm{~mL}$ ): proteins $3.2 \mathrm{~g}$, sugars $5 \mathrm{~g}$, lipids $1.55 \mathrm{~g}$ (including $0.9 \mathrm{~g}$ of saturated fat acids), alimentary fibers 0 , sodium $0.015 \mathrm{~g}$ (namely $0.13 \mathrm{~g}$ of salt), calcium $120 \mathrm{mg}$ ), (3) A real dairy wastewater provided from French industrial effluent; samples of raw wastewater were taken from secondary settling tank. When indicated $0.75 \%$ of a synthetic detergent containing $\mathrm{H}_{3} \mathrm{PO}_{4}(16.2 \%)$, $\mathrm{KOH}(11 \%)$ and $\mathrm{NaClO}(1 \%)$ was added to the diluted milk. 


\subsection{Inoculum}

A commercial consortium PL 4420 L 620442 provided by AQUAPROX (Levallois, France) of three filamentous fungi species, Aspergillus niger, Mucor hiemalis and Galactomyces geotrichum was used. These three fungi were found in the biological treatment tank of dairy wastewater. The consortium was designed to biodegrade fats, oils and greases of animal. The fungal suspension was packaged in an opaque tin container of $25 \mathrm{~L}$ in the form of a liquid mixture in presence of a nutrient medium, after use, it was stored at $4{ }^{\circ} \mathrm{C}$.

\subsection{Biodegradation tests}

\subsubsection{The $4 \mathrm{~L}$ lab-scale experiments}

It should be observed that preliminary experiments showed the relevance of culture medium aeration and that the optimal inoculum volume was $33 \mathrm{~mL}$ for $1 \mathrm{~L}$ medium (inoculum ratio $3.3 \% \mathrm{~V} / \mathrm{V}$ ).

When indicated and to optimize fungal activity, before inoculation the fungal consortium can be accelerated with $24 \mathrm{hr}$ aerated and agitated pre-cultivation at ambient temperature; for this purpose the pre-culture medium consisted of whey or sugar cane molasses diluted to achieve a lactose or a total sugar content of $5 \mathrm{~g} / \mathrm{L}$ respectively, or the dairy effluent itself and was also inoculated at $3.3 \%(V / V)$ by the fungal consortium.

All tests were conducted in batch and perfectly shaken media. Lab-scale experiments were carried out in $5 \mathrm{~L}$ beakers, at a working volume of $4 \mathrm{~L}$ and at ambient temperature and magnetically stirred. Aeration was performed by means of an aquarium pump connected to a diffuser allowing the production of fine air bubbles to ensure an efficient oxygen transfer. Inoculation $(3.3 \% \mathrm{~V} / \mathrm{V})$ of the fungal consortium accelerated or not) was performed after oxygen saturation of the culture medium. To be the nearest to the real conditions, culture media were not sterilized.

For each culture medium, the following set of experiments was carried out, which consisted of four different runs: the culture medium inoculated with non-accelerated fungi, with the fungal consortium accelerated on whey or molasses diluted to achieve $5 \mathrm{~g} / \mathrm{L}$ lactose or total sugar content, and with the fungal consortium accelerated on the same medium, as well as a blank experiment which consisted of non-inoculated culture medium.

\subsubsection{Pilot-scale experiments}

For a validation of the above results, experiments were carried out at a pilot-scale. For this purpose, $1600 \mathrm{~L}$ tank stainless steel from a dairy factory was used; its dimensions 
(Height*Width*Depth) were $800 \mathrm{~cm} \times 600 \mathrm{~cm} \times 280 \mathrm{~cm}($ Fig. 1). The working volume was 110 L. It was agitated to ensure homogeneity and appropriate dissolved oxygen amount.

Fig. 1 Schematic diagram of the $1600 \mathrm{~L}$ pilot tank.

The choice of the air sprinklers was based on the $\mathrm{K}_{\mathrm{L}}$ a value of the pilot tank as seen below (see 2.2), determined by the dynamic method, as described by Leveaux and Bouix (1998). Experiments were carried out on dairy wastewater, inoculated by the fungal consortium (3.3\% inoculation level $V / V)$ accelerated on the same effluent during $24 \mathrm{~h}(3.3 \%$ inoculation level $V / V$ ).

\subsubsection{Industrial scale experiments}

At an industrial scale, pre-culture were carried out in a resin $1000 \mathrm{~L}$ pilot, at a working volume of 600 L. The pilot was made in France by the company Novamax and its tank was in stainless steel. The pilot-scale had the following characteristics: 2 centrifugal pumps of $3 \mathrm{~kW}$ each, 1 AxFlow agitator, 5 valves drain and 2 pump isolation valves. To ensure homogenisation and aeration, the pilot contained an agitator.

Wastewater from the biological tank of a dairy wastewater treatment plant supplemented with $2 \mathrm{~g} / \mathrm{L}$ whey, namely $1.4 \mathrm{~g} / \mathrm{L}$ lactose, was used as a pre-culture medium for fungal consortium acceleration. The amount of lactose added was chosen based on the experiments dealing with the amount of lactose (whey) supplementation presented thereafter. Once a month the tank was re-inoculated with the fungal consortium $(3.3 \% \mathrm{~V} / \mathrm{V})$, and every two days a solution of $2 \mathrm{~g} / \mathrm{L}$ whey (70\% lactose) solution was added in the pilot tank to maintain the working volume constant. The $24 \mathrm{~L}$ of pre-culture was daily added in the biological tank by means of a pump programmed to operate $30 \mathrm{~min}$ daily. Inlet and outled $\mathrm{COD}$ values were daily monitored, while $\mathrm{BOD}_{5}$ values were weekly measured in the biological tank.

\subsection{Analytical methods}

Samples of $10 \mathrm{~mL}$ were periodically taken, which were centrifuged at $4000 \mathrm{r} / \mathrm{min}$ and $4{ }^{\circ} \mathrm{C}$ during $15 \mathrm{~min}$. The Chemical Oxygen Demand (COD) was measured initially (before centrifugation) and on the supernatant using the $\mathrm{HACH}$ method $(25-1500 \mathrm{mg} / \mathrm{L}$ range) in 
COD vials (CSB-Kuvettentest, Merck, Darmstadt, Germany), which involves heating at 150 ${ }^{\circ} \mathrm{C}$ during $2 \mathrm{hr}$ and then spectrophotometric reading (spectrophotometer SECOMAM, Alès, France). Total and soluble COD corresponding to the values found for the raw wastewater and the supernatant, respectively. Total sugars (determined spectrophotometrically by the phenol-sulphuric acid method, Herbert et al., 1971) was also monitored on the supernatant.

\section{Results and discussion}

\subsection{Lab-scale experiments}

\subsubsection{Study of the biodegradation on whey (Euroserum) solution -- Influence of the lactose concentration}

It was assumed that microorganisms beforehand cultivated on whey may display a reduced lag phase during degradation of the dairy wastewater. Indeed, lactose would be therefore the major sugar in both the pre-culture medium and the wastewater to be treated, leading to a prior acclimation of microorganisms to the major substrate (Pirt, 1985).

The following experimental protocol was considered to examine the effect of the lactose concentration on biodegradation, which consisted in the addition of a range of sweet whey powder (Euroserum) (70\% lactose) to distilled water to achieve lactose concentrations 2.5, 5.0, 7.5 and $15 \mathrm{~g} / \mathrm{L}$. Culture medium was aerated and agitated at ambient temperature for $2 \mathrm{~h}$ and inoculated with non-accelerated fungal consortium $(3.3 \% \mathrm{~V} / \mathrm{V})$.

The yields of lactose and COD removal recorded after $90 \mathrm{~h}$ of culture are given in Fig. 2 Irrespective of the initial lactose amount, only slight differences can be observed dealing with COD removal yields, contrarily to lactose consumption yields. Hence, the initial lactose amount did not have a significant impact on the degradation of the organic matter (OM). It should be noted that the low increase of the organic matter observed at the end of culture (not shown) can be attributed to cellular lysis, in agreement with a previous report dealing with activated sludge from wastewater treatment plant (Jeong, 1995).

Fig. 2 Yields of lactose (a) and COD removal (b) during non-accelerated fungal consortium growth on reconstituted sweet whey to achieve various initial lactose concentrations. 


\subsubsection{Study of the biodegradation on a synthetic dairy wastewater}

The objective was to show the efficiency of fungi for the biodegradation of dairy effluents. For this purpose, a synthetic effluent based on UHT sterilized milk diluted 40 times was considered. The following set of runs was carried out: $1 \mathrm{~L}$ of synthetic wastewater inoculated $(3.3 \% \mathrm{~V} / \mathrm{V})$.with non-accelerated fungi or accelerated for $48 \mathrm{~h}$ on whey diluted to achieve $5 \mathrm{~g} / \mathrm{L}$ lactose, as well as a blank experiment which consisted of non-inoculated dairy wastewater.

When cells were in exponential growth phase (Fig. 3a), a peak of the rate of degradation of the organic matter was observed (Fig. 3b). Figure $3 b$ shows that the addition of fungi improved COD removal, if compared to the endogenous microorganisms (blank test). In addition, fungal acceleration (pre-cultivation) improved somewhat the rate of COD removal if compared to non-accelerated fungi (Fig. 3b), since the former cells were adapted to lactose assimilation.

Owing to the positive impact of the fungal inoculation on one hand and the fungal acceleration on the other hand, additional experiments were carried out with fungi accelerated on molasses to compare to whey acceleration. As can be seen from Fig. 3a, from 1 day of culture an increase of the cell dry weight was observed. As expected, the higher growth rate was observed for the culture medium inoculated with fungi accelerated on whey; while fungal acceleration on molasses did not yield to a similar growth rate. It should be most likely attributed to the nature of the sugar contained in both pre-cultivation media, sucrose for sugar cane molasses and lactose for whey, namely that of the culture medium, milk. Contrarily at the end of culture, final biomass concentrations were nearly similar for both experiments.

Fig. 3 Time-courses of dry cell weight (a) and COD concentrations (b) during growth on dairy wastewater

Comparison of the non-inoculated synthetic medium (endogenous microorganisms) and that inoculated with non-accelerated fungi showed as expected a higher growth rate for the latter confirming the positive impact of the fungal consortium (Fig.3a), and lower than those recorded in presence of accelerated fungi. In addition, final biomass concentrations were lower than those recorded in presence of accelerated fungi, confirming the impact of the non-assimilated sugars coming from the inoculum. 
Figure $3 \mathbf{b}$ shows that the addition of fungi improved COD removal, if compared to the endogenous microorganisms (blank test), about 75 and 54\% respectively. In addition, fungal acceleration on whey improved the rate of removal if compared to fungal acceleration on molasses and non-accelerated fungi (Fig. 3b), since the former cells were adapted to lactose assimilation; while final removal yields were nearly similar in case of fungal acceleration (75-76\%) and slightly lower in absence of beforehand fungal acceleration (69\%).

To approach the real conditions which can be found in industrial dairy wastewater, similar experiments have been carried out after adding $0.75 \%$ of a synthetic detergent. Its addition did not have a negative impact on growth, but a positive one since final biomass concentrations were in the range 1.65-1.9 $\mathrm{g} / \mathrm{L}$, except in absence of fungal inoculation (endogenous microorganisms), $1.3 \mathrm{~g} / \mathrm{L}$. This positive effect should be most likely related to the presence of phosphorous in the detergent (16.2\%).

The detergent addition $(0.75 \%)$ was added on non-accelerated fungi or accelerated fungi on reconstituted whey powder (5 g/L lactose) or accelerated fungi on sugar cane molasses diluted to obtain $5 \mathrm{~g} / \mathrm{L}$ total sugars, as well as non-inoculated culture medium. This addition did not affect significantly organic matter removal, since final yields of COD removal were 75 and 72 $\%$ in case of inoculation with fungi accelerated on whey and molasses respectively, confirming the higher efficiency of lactose for fungal preculture. Contrarily, lower removal yields were recorded in absence of fungal acceleration and during endogenous microorganisms growth, 61 and 55\% respectively.

The above results show the positive impact of fungal acceleration. While in absence of acceleration, the impact of fungal addition on growth appeared not really significant, most likely due to their storage at $4^{\circ} \mathrm{C}$.

\subsubsection{Study of the biodegradation on the real dairy wastewater}

As for the synthetic effluent, experiments were carried out on the real dairy wastewater inoculated with the fungal consortium accelerated by pre-cultivation during $48 \mathrm{~h}$ on whey ( $5 \mathrm{~g} / \mathrm{L}$ lactose) or on the same medium (dairy wastewater), or non-accelerated fungi, as well as in absence of fungal inoculation (control test). For all runs, an initial increase of COD was recorded, followed by a decrease until about $50 \mathrm{~h}$ of culture, and then a COD increase until the end of culture (Fig. 4). 
Fig. 4 Time-courses of COD concentrations during growth on real dairy wastewater

In a first step, the fungi and/or the endogenous flora hydrolyzed some macromolecules leading to an increase of the total COD, and hence the production of soluble daughter molecules illustrated by the concomitant increase of the soluble COD (not shown), which was then assimilated by the microorganisms illustrated by the total COD decrease (Fig. 4). However, a lower decrease of the soluble COD was recorded for the control test (not shown), namely in presence of the endogenous microorganisms. The final increase of the total COD may be attributed to the release of the intracellular material following cellular lysis. Indeed, transient COD increase has been previously reported during the biodegradation of synthetic dairy effluents, which can be attributed to the release of soluble compounds contained in the suspended solids (Jeong, 1995; De Campins, 2005) or to the breaking down of the microbial floc (Mannan et al., 2005).

\subsection{Determination of the mass transfer coefficients}

Gas-liquid mass transfer can be described by Eq. (1) (Leveaux \& Bouix, 1998).

$$
\frac{d C_{L}}{d t}=K_{L} a\left(C^{*}-C_{L}\right)
$$

where, $\mathrm{C}_{\mathrm{L}}$ and $\mathrm{C}^{*}$ are the $\mathrm{O}_{2}$ concentrations in the liquid phase (dairy wastewater) and equilibrium with the gas phase respectively, $\mathrm{K}_{\mathrm{L}}$ is the overall $\mathrm{O}_{2}$ mass transfer coefficient in the liquid phase, a is the specific gas/liquid interfacial area and $\mathrm{K}_{\mathrm{L}} \mathrm{a}$ the volumetric mass transfer coefficient.

To determine the $\mathrm{K}_{\mathrm{L}}$ a values for the lab-scale pilot tank $(110 \mathrm{~L})$, oxygen was saturated by means of ceramic air sprinklers or plane sprinklers (stone) and air injection at a flow rate of $400 \mathrm{~L} / \mathrm{h}$. During cessation of aeration and then after resumption of aeration, oxygen amount was measured every minute according to the protocol of Leveaux and Bouix (1998), allowing the determination of the $\mathrm{K}_{\mathrm{L}}$ a values, which were 0.236 and $0.233 \mathrm{~min}^{-1}$ for the two ceramic air sprinklers of $150 \mathrm{~mm}$ length and for the plane sprinkler of $250 \mathrm{~mm}$ length respectively. Since close $\mathrm{K}_{\mathrm{L}} \mathrm{a}$ values were found, the plane sprinklers were chosen for their higher length and their easiness to be implemented in the tank (plane sprinklers).

The results recorded in the pilot tank (110 L) (Fig. 5) were similar to those recorded at lab-scale (Fig. 3) showing an absence of volume effect on the biodegradation of the organic 
matter, which appeared promising for a subsequent extrapolation at industrial scale (biological tank of the wastewater treatment plant).

Fig. 5 Time-courses of COD concentrations during growth on dairy wastewater, inoculated with the fungal consortium (3.3\% inoculation level) accelerated on the same effluent during $24 \mathrm{hr}$.

The increase of the total COD recorded during the first day of culture showed the transfer of non-soluble to soluble COD, leading to more biodegradable molecules, available for growth of activated sludge found in the biological tank.

\subsection{Industrial scale experiments}

$\mathrm{COD}$ and $\mathrm{BOD}_{5}$ measurements have been carried out at the inlet and the outlet of the industrial biological tank, daily and weekly for $\mathrm{COD}$ and $\mathrm{BOD}_{5}$ respectively. During tests on site, the inlet COD varied between 1500 and $2000 \mathrm{mg} \mathrm{O}_{2} / \mathrm{L}$.

Fig. 6 COD measurements at the outlet of the industrial biological tank from a dairy factory inoculated with the fungal consortium accelerated by pre-cultivation on dairy wastewater supplemented with $2 \mathrm{~g} / \mathrm{L}$ whey (70\% lactose) in a $1000 \mathrm{~L}$ pilot plant.

Before Fungal addition after 8 days of experiment, COD values at the outlet of the biological tank increased until a value of $124 \mathrm{mg} / \mathrm{L}$ at day 8 (Fig. 5). After the addition of the fungal consortium accelerated on the same medium (real dairy wastewater), the increase continued until day 10 (139 mg/L, Fig. 6), before a continuous decrease recorded until approximately day 20. From this time and until the end of the experiment at day 32, COD values remained roughly in the range $50-70 \mathrm{mg} / \mathrm{L}$, namely significantly below the standard value $(100 \mathrm{mg} / \mathrm{L})$. It should be noted that the trend was similar to that observed at a lower scale (lab-scale and pilot scale). Indeed, in a first step, the fungi and/or the endogenous flora hydrolyzed some macromolecules leading to an increase of the COD, and hence the 
production of soluble daughter molecules, which was then assimilated by the microorganisms illustrated by the total COD decrease.

To examine the impact of fungal addition on the 'hard' or non-biodegradable COD, the $\mathrm{COD}$ on $\mathrm{BOD}_{5}$ ratio were examined (Table 1). Before regular addition of fungi, the increase of the $\mathrm{COD}$ on $\mathrm{BOD}_{5}$ ratio were 451 and $1111 \%$, showing a significant increase of the 'hard' COD between the inlet and the outlet, and hence the production of refractory COD in the biological tank. This phenomenon has been also previously reported during the treatment of urban wastewater using activated sludge (Jeong, 1995).

Table 1 Variation of the $\mathrm{COD}$ on $\mathrm{BOD}_{5}$ ratio at the inlet and the outlet of the biological tank

\begin{tabular}{cccc}
\hline Day & Inlet COD/BOD & Outlet COD/BOD & Variation $(\%)$ \\
\hline $1^{\mathrm{a}}$ & 1.76 & 7.96 & 451 \\
\hline $8^{\mathrm{a}}$ & 1.64 & 18.17 & 1111 \\
\hline $15^{\mathrm{b}}$ & 2.95 & 7.59 & 257 \\
\hline $22^{\mathrm{b}}$ & 4.41 & 6.75 & 153
\end{tabular}

${ }^{a}$ Before fungal inoculation, ${ }^{b}$ after implementation of the fungal inoculation.

After addition of the fungal consortium in the biological tank, a clear decrease of the $\mathrm{COD}$ on $\mathrm{BOD}_{5}$ ratio between the inlet and the outlet, 257 and $153 \%$, showing a clear positive impact of the fungal addition on the production of refractory COD.

\section{Conclusions}

The efficiency of the addition of consortium of three filamentous fungi species, Aspergillus niger, Mucor hiemalis and Galactomyces geotrichum for the bio-augmentation of the endogenous microorganisms (activated sludge) contained in dairy wastewater was examined.

The positive impact of fungal addition on COD removal was confirmed when fungi was beforehand accelerated by pre-cultivation on the same medium, since COD removal increased from $55 \%$ in absence of fungi to $75 \%$ after their addition. In addition, this positive impact was confirmed not only at lab-scale level, but also at industrial scale. Indeed, after inoculation of an industrial biological tank from a dairy factory with the fungal consortium accelerated by pre-cultivation in a $1000 \mathrm{~L}$ pilot plant, there was not only an increase of the COD removal yield, but also a positive effect on the 'hard' or non-biodegradable COD since the increase of the $\mathrm{COD}$ on $\mathrm{BOD}_{5}$ ratio between the inlet and the outlet of the biological tank 
was significantly reduced. It was in the range $451-1111 \%$ before fungal add, and in the range 257 and $153 \%$ after bio-augmentation with fungi.

A tertiary treatment could be proposed to finalize the biological treatment of industrial effluents, which appear however expensive, contrarily to the proposed Bio-augmentation by the addition of a fungal consortium. An inoculated bioreactor robustness and reliability was developed at lab-scale and demonstrated successfully at pilot-scale.

\section{References}

Alvareza N, Gesan-Guiziou G, Daufin G, 2007. The role of surface tension of re-used caustic soda on the cleaning efficiency in dairy plants. International Dairy Journal, 17: 403-11.

Balannec B, Vourch M, Rabiller-Baudry M, Chaufer B, 2005. Comparative study of different nanofiltration and reverse osmosis membranes for dairy treatment by dead-end filtration. Separation Purification Technology, 42: 195-200.

Beary P, Boopathy R, Templet P, 2002. Accelerated decomposition of sugarcane crop residue using a fungal-bacterial consortium. International Biodeterioration and Biodegradation, 50: 41-46.

Bhalerao T S, Puranik P R, 2006. Biodegradation of organochlorine pesticide, endosulfan, by a fungal soil isolate, Aspergillus niger. International Biodeterioration and Biodegradation, 59: 315-321.

Chen J, Zhan P, Koopman B, Fang G, Shi Y, 2012. Bioaugmentation with Gordonia strain JW8 in treatment of pulp and paper wastewater. Clean Technology Environmental Policy, 14(5): 899-904.

Del Re G, Di Giacomo G, Aloisio L, Terreri M, 1998. RO treatment of waste waters from dairy industry. Desalination, 119: 205-206.

Deepak D, Anand K V, Bhargarva R, 1994, Biodegradation kinetics of metal cutting oil : evaluation of kinetic parameters, Chemical engineering journal 56, B91-96.

Demirel B, Yenigun O, Onay T T, 2005. Anaerobic treatment of dairy wastewaters: a review. Process Biochemestry, 40: 2583-2595.

Djelal H, Perrot M, Grisard D, 2007. Utilisation de champignons spécifiques pour la biodégradation d'effluents industriels, L'Eau, l'Industrie et les Nuisances, 306: 8591 , in french. 
Giraud F, Guiraud P, Kadri M, Blake G, Steiman R, 2001. Biodegradation of anthracene and fluoranthene by fungi isolated from an experimental constructed wetland for wastewater treatment. Water Research, 35(17): 4126-4136.

Herbert D, Phipps P J, Strange R E, 1971. Chemical analysis of microbial cells. In: Methods in microbiology (Norris J R, Ribbons D W, eds.). Academc Press, London. 5B: 265--308.

Huang X, Liang P, Qian Y, 2007. Excess sludge reduction induced by Tubifex tubifex in a recyced sludge reactor. Journal biotechnology, 127: 443-451.

Kushwaha J P, Srivastava V C, Mall I D, 2010. Organics removal from dairy wastewater by electrochemical treatment and residue disposal. Separation Purification Technology, 76: 198-205.

Lapadatescu C, Barbe E, Coudurier Y, 2010. Use of filamentous fungi in waste water treatment plants: Site of Saint Louis Sucre-Marseille. L'Eau, l'Industrie et les Nuisances, 336, 145-148.

Leveau J Y, Bouix M, 1988. Biotechnologie (Scriban R ed., 5th ed.). Lavoisier, Paris. 229-310.

Loperena L, Saravia D, Murro C, Ferrari M D, Lareo C, 2006. Kinetic properties of a commercial and a native inoculum for aerobic milk fat degradation. Bioresource Technology, 97: 2160-2165.

Loperena L, Ferrari M D, Saravia D, Murro C, Lima C, Ferrando L, Fernandez A, Lareo C, 2007. Performance of a commercial inoculum for the aerobic biodegradation of a high fat content dairy wastewater. Bioresource Technology, 98: 1045-1051.

Low E U, Chase H A, 1999. Reducing production of excess biomass during wastewater treatment. Water Research, 33(5): 1119-1132.

Luo J, Ding L, Qi B, Jaffrin M Y, Wan Y, 2011. A two-stage ultrafiltration and nanofiltration process for recycling dairy wastewater. Bioresource Technology, 102: 7437--7442.

Jeong Y D, 1995. Characterization of refractory organics matter in the wastewater using biological treatment methods, Ph.D. thesis, National Institute of Applied Sciences in Toulouse.

Mannan, S, Fakhru'l-Razi A, Zahangir Alam M, 2005. Use of fungi to improve bioconversion of activated sludge. Water Research, 39(13): 2935-2943.

Moir S E, Svoboda I, Sym G, Clark J, McGechan M B, Castele K, 2005. An experimental plant for testing methods of treating dilute farm effluents and dirty watter. Biosystems Engineering, 90(3): 349-355. 
Morin S, Whalen J K, Barrington S, Lin X, 2007. Soil Nutrient Load and Drain Water Quality in Seepage Fields Receiving Milk House Wastewater. Water Air Soil Pollution, 181: 51-63.

Muangrat R, Onwudili J A, Williams P T, 2011. Alkaline subcritical water gasification of dairy industry waste (Whey). Bioresource Technology, 102: 6331-6335.

Sarkar B, Chakrabarti P P, Vijaykumar A, Kale V, 2006. Wastewater treatment in dairy industries-possibility of reuse. Desalination, 195: 141-152.

Seesuriyachan P, kuntiya A, Sasaki K, Techapun C, 2009. Biocoagulation of dairy wastewater by Lactobacillus casei TISTR 1500 for protein recovery using micro-aerobic sequencing batch reactor (micro-aerobic SBR). Process Biochemestry, 44: 406-411.

Wei Y S, Van H R T, Borger A R, Eikelboom D H, Fan Y B, 2003a. Comparaison performances of membrane bioreactor (MBR) and conventional activated sludge (CAS) processes on sludge reduction induced by Oligochaete. Environnemental Science Technology, 37(14): 3171-3180.

Wei Y S, Van H R T, Borger A R, Eikelboom D H, Fan Y B, 2003b. Minimizing of excess sludge production for biological wastewater treatment. Water Research, 37(18): 4453-4467.

Wu X, Dong C, Yao W, Zhu J, 2011. Anaerobic digestion of dairy manure influenced by thewaste milk from milking operations. Journal of Dairy Science, 94: 3778-3786.

www.aquatech.limoges.free.fr/../C.\%20MaurizeResume\%20MycET.pdf, consulted January 5, 2013.

www.paysdeluxeuil.fr, consulted January 5, 2013.

www.novethic.fr/novethic/entreprise/environnement, consulted January 5, 2013 


\section{Figure captions}

Fig. 1 Schematic diagram of the $1600 \mathrm{~L}$ pilot tank.

Fig. 2 Yields of lactose and COD removal during non-accelerated fungal consortium growth on reconstituted sweet whey to achieve initial lactose concentrations.

Fig. 3 Time-courses of dry cell weight (a) and COD concentrations (b) during growth on dairy wastewater.

Fig. 4 Time-courses of COD concentrations during growth on real dairy wastewater.

Fig. 5 Time-courses of COD concentrations during growth on dairy wastewater, inoculated with the fungal consortium (3.3\% inoculation level $V / V)$ accelerated on the same effluent during $24 \mathrm{hr}$.

Fig. 6 COD measurements at the outlet of the industrial biological tank from a dairy factory inoculated with the fungal consortium accelerated by pre-cultivation on dairy wastewater supplemented with $2 \mathrm{~g} / \mathrm{L}$ whey (70\% lactose) in a $1000 \mathrm{~L}$ pilot plant; 


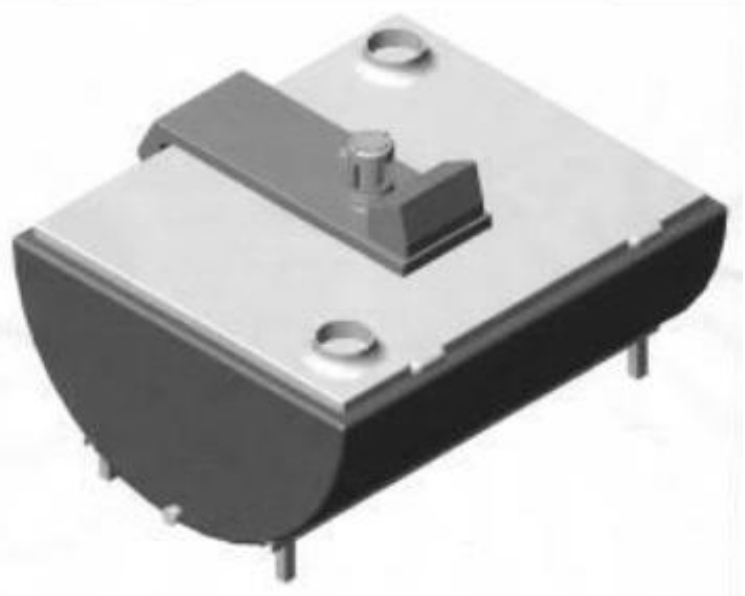

Fig. 1 Schematic diagram of the 1600 L pilot tank.

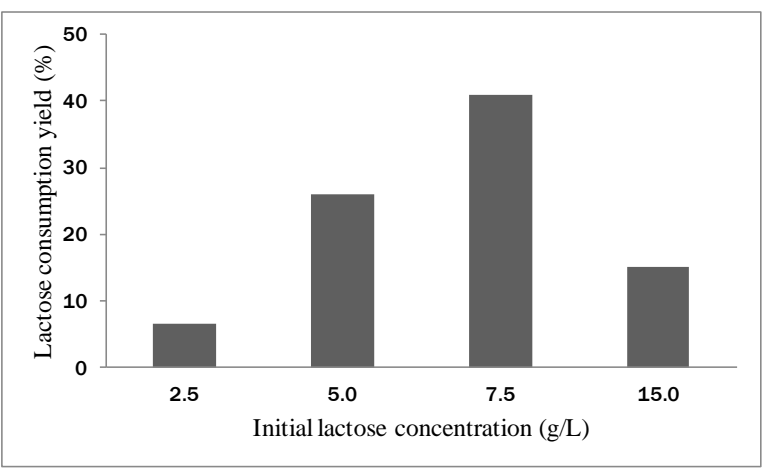

(a)

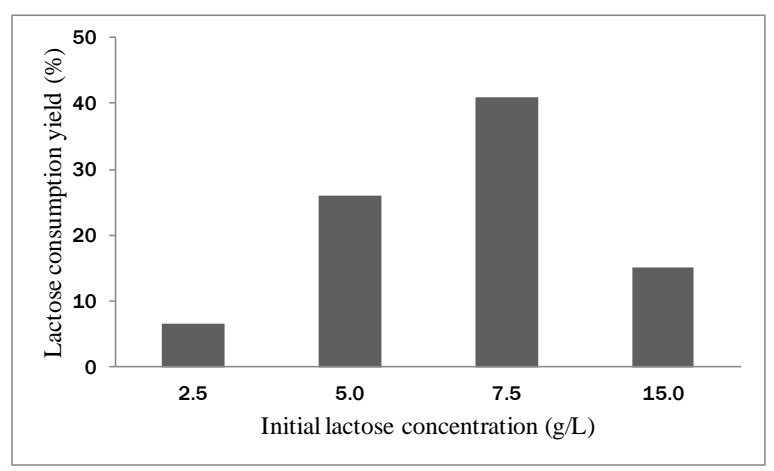

(b)

Fig. 2 Yields of lactose (a) and COD removal (b) during non-accelerated fungal consortium growth on reconstituted sweet whey to achieve initial lactose concentrations. 


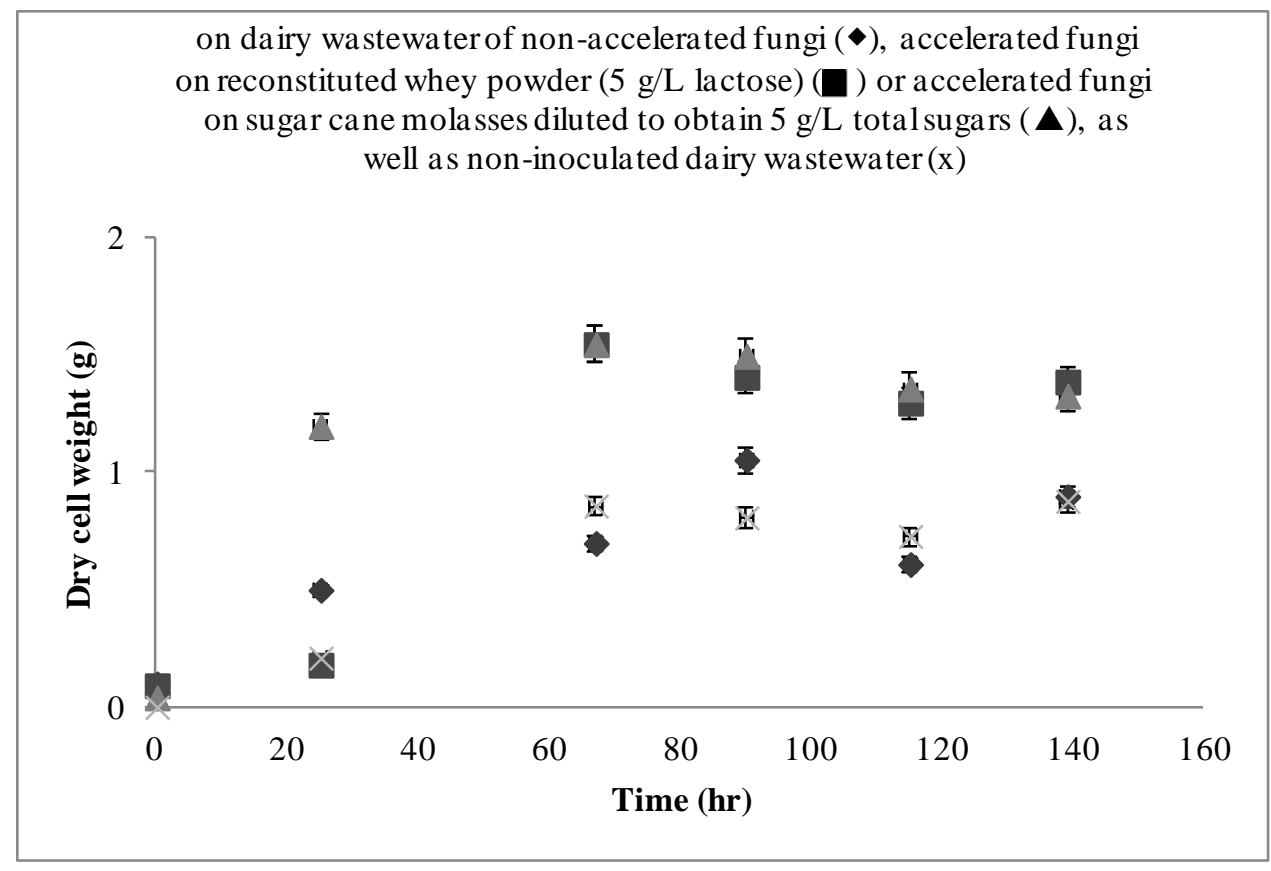

(a)

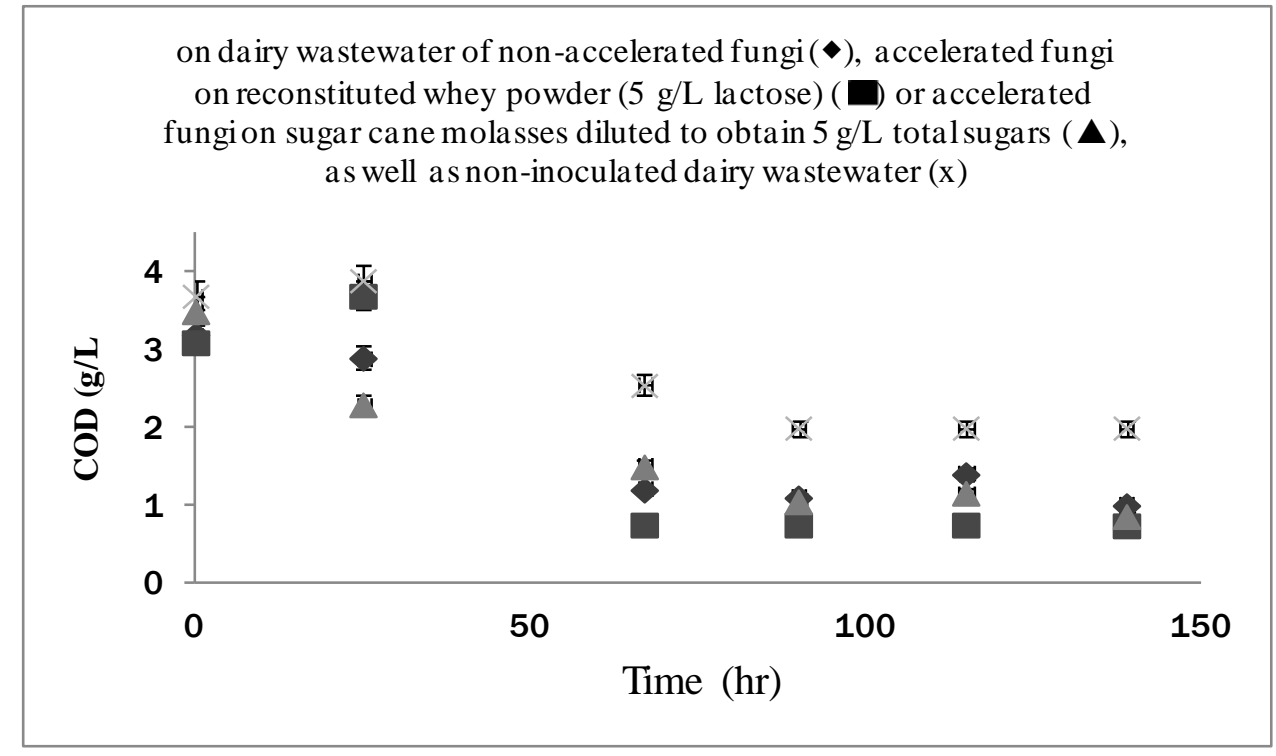

(b)

Fig. 3 Time-courses of dry cell weight (a) and COD concentrations (b). 


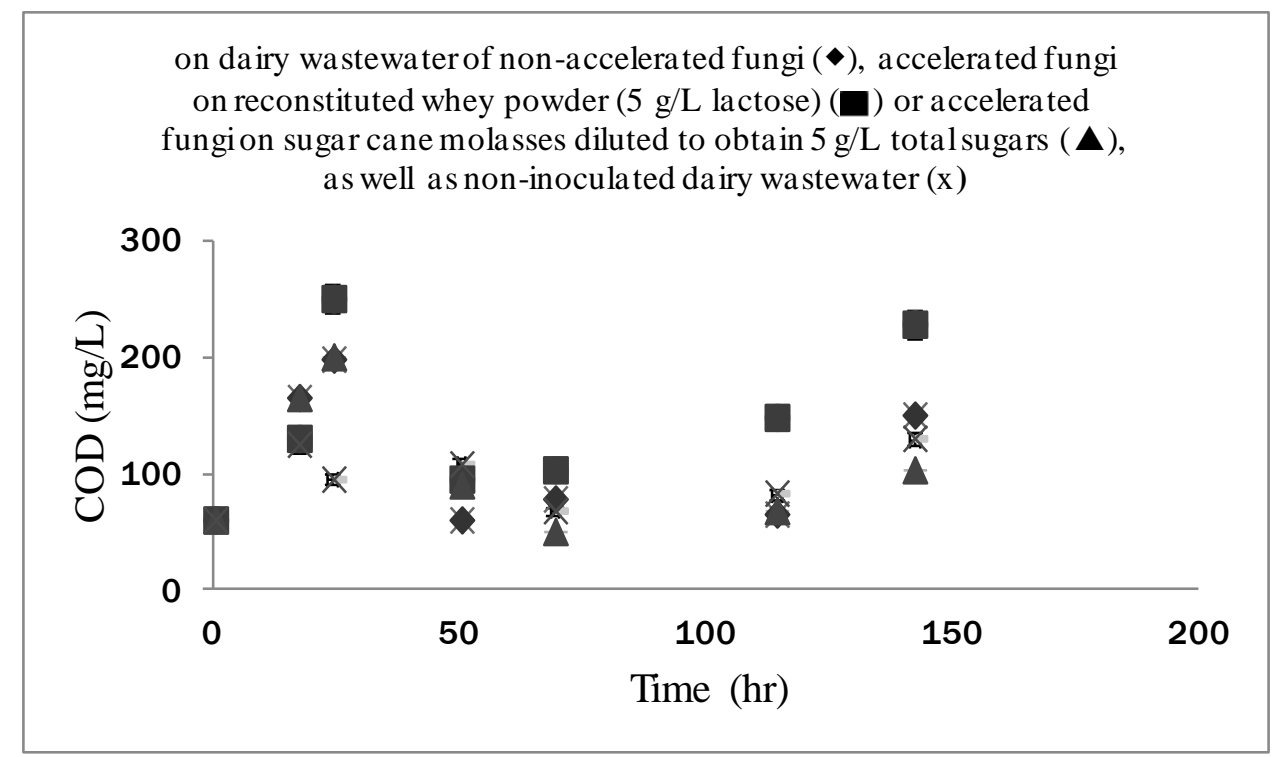

Fig. 4 Time-courses of COD concentrations during growth on real dairy wastewater.

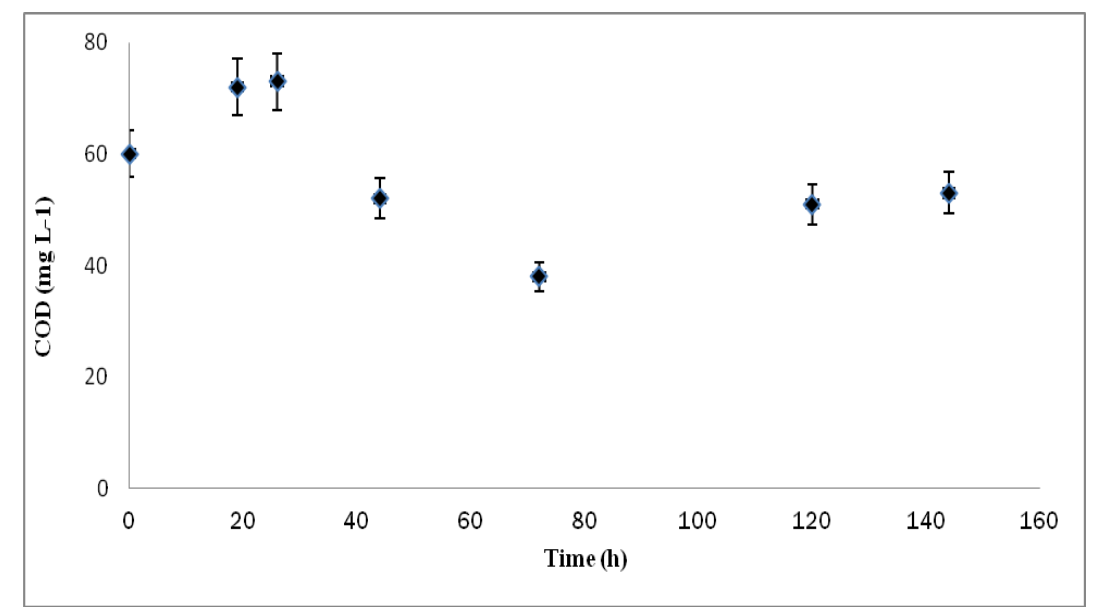

Fig. 5 Time-courses of COD concentrations during growth on dairy wastewater, inoculated with the fungal consortium (3.3\% V/V inoculation level) accelerated on the same effluent during $24 \mathrm{hr}$. 


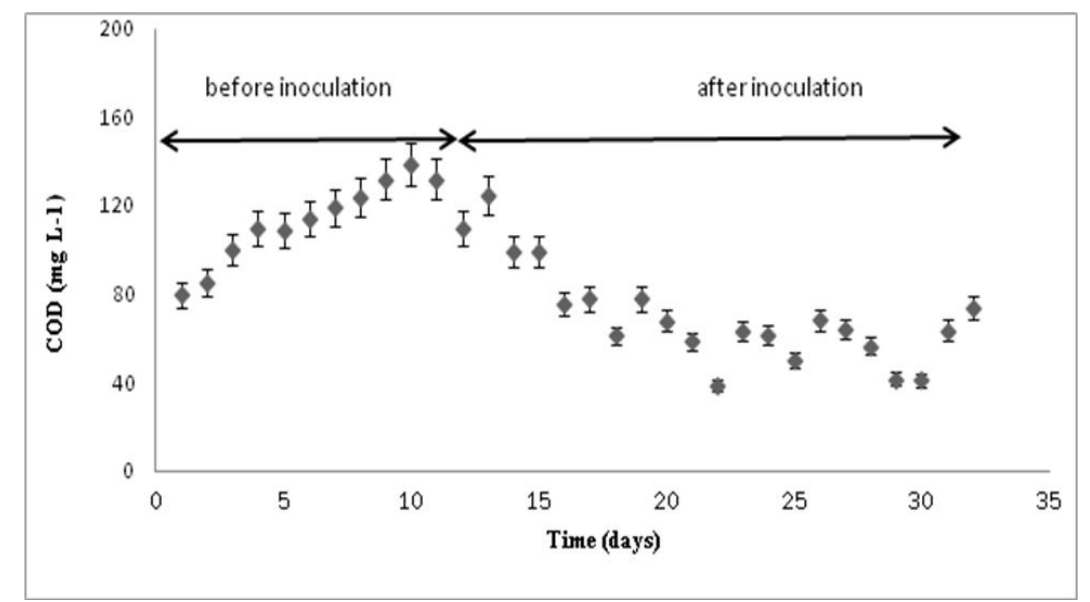

Fig. 6 COD measurements at the outlet of the industrial biological tank from a dairy factory inoculated with the fungal consortium accelerated by pre-cultivation on dairy wastewater supplemented with $2 \mathrm{~g} / \mathrm{L}$ whey (70 \% lactose) in a $1000 \mathrm{~L}$ pilot plant. 